\title{
Differences in the macrozoobenthic fauna colonising empty bivalve shells before and after invasion by Corbicula fluminea
}

\author{
M. I. Ilarri ${ }^{\mathrm{A}, \mathrm{B}, \mathrm{D}}$, A. T. Souza ${ }^{\mathrm{A}}$, V. Modesto $^{\mathrm{A}}$, L. Guilhermino $^{\mathrm{A}, \mathrm{B}}$ and R. Sousa ${ }^{\mathrm{A}, \mathrm{C}}$ \\ A Interdisciplinary Centre of Marine and Environmental Research (CIIMAR/CIMAR), \\ University of Porto, Rua dos Bragas 289, PT-4050-123 Porto, Portugal. \\ ${ }^{B}$ ICBAS-UP - Abel Salazar Biomedical Sciences Institute, University of Porto, \\ Rua de Jorge Viterbo Ferreira, 228, PT-4050-313, Porto, Portugal. \\ ${ }^{\mathrm{C}} \mathrm{CBMA}$ - Centre of Molecular and Environmental Biology, Department of Biology, \\ University of Minho, Campos de Gualtar, PT-4710-057 Braga, Portugal. \\ ${ }^{\mathrm{D}}$ Corresponding author. Email: martinailarri@gmail.com
}

\begin{abstract}
Bivalve shells can potentially alter the structure of aquatic benthic communities. However, little is known about the effect that different shell morphologies have on their associated fauna. This study aimed to understand how empty shells, from four different freshwater bivalve species, affect macrozoobenthic communities, using the River Minho (Iberian Peninsula) as a study area. Three native (Anodonta anatina, Potomida littoralis, Unio delphinus) and one non-indigenous (Corbicula fluminea) species were used for this research. Comparisons among species and between scenarios (i.e. before and after invasion by $C$. fluminea) were performed. Our results suggest that macrozoobenthic community structure did not vary among treatments, with the exception of species richness, which was higher on shells of native species. Furthermore, little difference was detected when comparing scenarios with and without $C$. fluminea shells, despite dissimilarities in size and morphology between species. The empty shells of $C$. fluminea partially (in terms of density and biomass, but not in species richness) replaced the role of empty shells of native species as a physical substratum for the associated macrozoobenthic community.
\end{abstract}

Additional keywords: biodiversity, macrozoobenthos, non-indigenous species, River Minho, shell size.

Received 9 January 2014, accepted 24 September 2014, published online 29 January 2015

\section{Introduction}

Bivalves can significantly influence the community structure and ecosystem processes and functions (e.g. primary and secondary production and the nutrient cycle) of freshwater habitats (Vaughn and Hakenkamp 2001; Strayer 2009). This can result from several mechanisms, including filter feeding, bioturbation activities and shell production (Sousa et al. 2009, 2014). The changes mediated by the presence of a new substratum provided by their shells can lead to new interactions or process pathways even after the death of the bivalve (Karatayev et al. 2007; Sousa et al. 2009; Bódis et al. 2014). Bivalve shells influence the ecology of a variety of aquatic organisms, including sponges, cnidarians, ascidians, echinoderms, bryozoans, crustaceans, fish and many others (Nyman 1953; Corriero and Pronzato 1987; Buchman et al. 2007; Rabaoui et al. 2007). In most cases, bivalve shells are used to avoid predators and competitors and to decrease physical and physiological stress (Gutiérrez et al. 2003). The abundance, size and distribution range of bivalve shells confer on them a high ecological importance as hard substrata ready for colonisation (Palacios et al. 2000; Gutiérrez et al. 2003; Erwin 2008).
Biological invasions have become a common and serious concern, causing severe economic and ecological impacts, and posing serious threats to native communities (Crooks 2002; Vilà et al. 2010, Simberloff et al. 2013). Such invasions are considered one of the major threats to freshwater biodiversity (Dudgeon et al. 2006; Strayer and Dudgeon 2010; Strayer 2010). Particularly important may be species that become dominant or are able to introduce new ecological attributes (Gutiérrez et al. 2014), such as invasive bivalve species (reviewed in Sousa et al. 2014). The Asian clam Corbicula fluminea is a successful invader of fresh and brackish waters, and is consequently considered one of the most problematic invasive species in Europe (DAISIE, European Invasive Alien Species Gateway, see http://www.europe-aliens.org/species TheWorst.do, accessed 4 January 2014). C. fluminea was first reported in Europe in the late 1970s and is now widespread throughout that continent, as well as in Africa, and North and South America (reviewed in Ilarri and Sousa 2012). This species is frequently described as a threat to several elements of ecosystems, including submerged vegetation, phytoplankton, zooplankton, macrozoobenthos and higher trophic levels, 


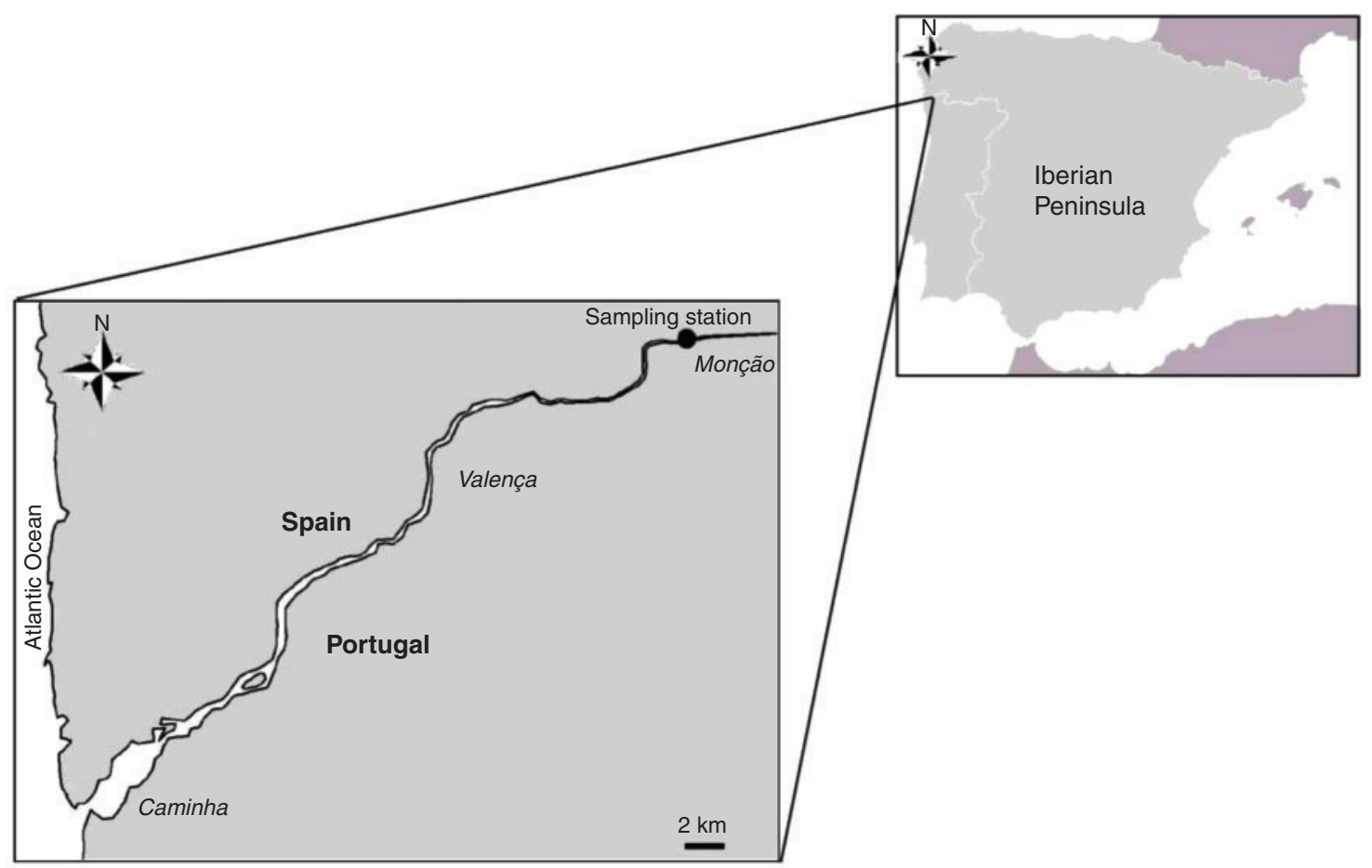

Fig. 1. Map of the study site showing where the treatments were located along the River Minho, in the north-west Iberian Peninsula.

leading to important economic losses (McMahon 2000, 2002; Sousa et al. 2008b, 2009).

Following the establishment of $C$. fluminea into the River Minho (in the north-west of the Iberian Peninsula) in 1989 (Araujo et al. 1993), the density of native bivalve species (e.g. Anodonta anatina, Potomida littoralis, Unio delphinus and Pisidium amnicum) has declined (Sousa et al. 2005, 2008b, $2008 c, 2011)$. C. fluminea is now the dominant species in the final $70 \mathrm{~km}$ of the River Minho (Sousa et al. 2008b, 2008d, 2008e). In a recent study, Ilarri et al. (2012) suggested that the engineering activities by $C$. fluminea individuals significantly influenced the macrozoobenthic community with several species being more abundant in areas where the density of C. fluminea was also higher. In previous studies performed with other bivalve species, the same effect has been observed (Ricciardi et al. 1997; Spooner and Vaughn 2006; Borthagaray and Carranza 2007). Nonetheless, other studies performed with live Corbicula individuals in other freshwater systems have found no significant effects on the macrozoobenthic community (Hakenkamp et al. 2001; Karatayev et al. 2003; Werner and Rothhaupt 2007). However, to date very little is known about the associated fauna colonising empty bivalve shells in aquatic ecosystems. Moreover, little is known about the effects of shells with different morphologies and origins (e.g. invasive or native) on the macrozoobenthic community.

In this context, the aims of the present study are: (1) to examine whether different bivalve species, represented by their empty shells, support a distinct associated fauna; and (2) to compare the associated fauna of the most abundant native bivalve species before invasion by $C$. fluminea (through simulated scenarios) with the current associated fauna of the bivalve species (predominantly dominated by the Asian clam C. fluminea).

\section{Material and methods}

Study area

The experiment was conducted in the River Minho (in the northwest of the Iberian Peninsula), $\sim 40 \mathrm{~km}$ from the river mouth (Fig. 1). The headwaters of the River Minho are located at the Serra de Meira (Spain), with $95 \%$ of the Minho hydrological basin situated in Spain, with the remaining 5\% in Portugal. The River Minho is $310 \mathrm{~km}$ long with a maximum width of $2 \mathrm{~km}$ near the mouth, flowing north-north-east to south-south-west into the Atlantic Ocean. The selected study area is very shallow (only $1 \mathrm{~m}$ deep during the summer) with permanent freshwater conditions. The substratum consists of gravel, sand, macrophytes and $C$. fluminea shells (live and empty). The water current varied from moderate to strong and these variations can be approximately correlated with the operations of a dam located $30 \mathrm{~km}$ upstream from the study site. However, during the study period the water current was always low. Over the 2 months of the experiment (June and July 2012), the mean water temperature ranged between 20.2 and $23.7^{\circ} \mathrm{C}$, conductivity between 71 and $85 \mathrm{~ms} \mathrm{~cm}^{-1}$, dissolved oxygen between 8.6 and $9.1 \mathrm{mg} \mathrm{L}^{-1}$, pH between 7.6 and 7.8 , and redox potential between 80.1 and $94.6 \mathrm{mV}$.

\section{Experimental design and laboratory procedures}

To study the effects of the bivalve shells on the associated macrozoobenthic community, empty shells of three native (A. anatina, $P$. littoralis and $U$. delphinus) and one non-native 
(a)

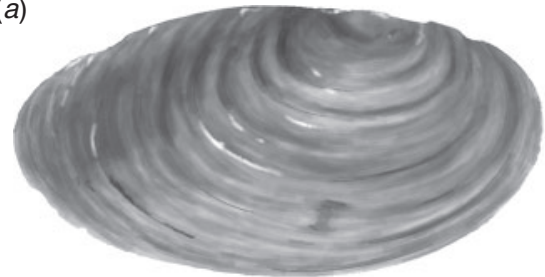

(c)

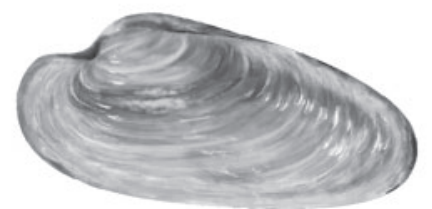

(b)

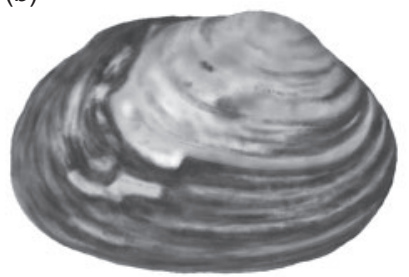

(d)

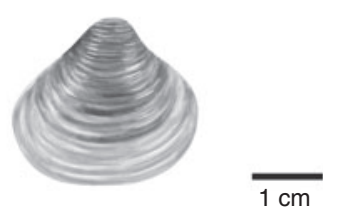

Fig. 2. Bivalve species used in the experiment: (a) Anodonta anatina, (b) Potomida littoralis, (c) Unio delphinus, and (d) Corbicula fluminea.

(C. fluminea) species were used (Fig. 2). The shells of the four bivalve species were manually cleaned in order to remove any traces of soft tissue, before placing the shells in individually sealed nylon net bags. As a standard we used only shells that were intact, usually belonging to an organism that recently died. Six different treatments were assigned: four treatments with shells of each individual species; one treatment with a mixture of native bivalve shells (one-third each of the three native species), simulating the River Minho scenario before the invasion by C. fluminea ('Mix natives'); and lastly one treatment with $90 \%$ of $C$. fluminea and $10 \%$ of native species evenly represented, simulating the scenario encountered on the River Minho now ('Mix actual'). The shell sizes used for the experiments represented sizes available in the field for each species. Furthermore, in order to avoid bias due to differences between species in the outer surface areas, an identical sum of the shells' outer surface area $\left(1200 \mathrm{~cm}^{2}\right)$ was used in all treatments. Bags with a mesh size of $10 \mathrm{~mm}$ were used in order to allow colonisation of the shells by macroinvertebrate species, while excluding larger animals. Six net bags (one per treatment) were tied with a string to a stake (a total of 10 stakes were used, $n=10$ per treatment), and placed under water $(\sim 70 \mathrm{~cm}$ deep $) \sim 10 \mathrm{~m}$ from the river bank (at the lowest water level). The bags remained under water for 2 months (June and July 2012), the time necessary to observe significant colonisation. At the end of the experiment, the macrozoobenthos associated with the empty shells were initially sieved using a $500-\mu \mathrm{m}$ mesh, and then sorted and fixed in $70 \%$ ethanol for later identification, using Tachet et al. (2003). Whenever species identification was not possible, specimens were identified to the lowest practical taxonomic level. After identification, all individuals were dried in an oven at $60^{\circ} \mathrm{C}$ for $24 \mathrm{~h}$ to determine their dry weight (DW).

\section{Data analysis}

Initially, a cluster analysis was performed to determine the similarities and relationships between treatments regarding the physical attributes of the shells (i.e. the size and the number of shells used in each treatment). For better data visualisation, the mean values of size and number of shells of each treatment were used in the resemblance matrix based on the Euclidean distances. Subsequently, Permutational Multivariate Analysis of Variance (PERMANOVA) was performed to explore possible differences in the associated macrozoobenthic community. This method analyzes the variance of multivariate data explained by a set of explanatory factors, on the basis of any chosen measure of distance or dissimilarity, thereby allowing for a wide range of empirical data distributions (Anderson 2001). The overall associated macrozoobenthic density, biomass and the density of the most representative faunal groups (Platyhelminthes, Mollusca, Annelida, Crustacea and Insecta) were statistically tested using a one-way PERMANOVA (Type III), with treatment as a fixed factor (six levels: 'Anodonta', 'Potomida', 'Unio', 'Corbicula', 'Mix natives' and 'Mix actual'). Prior to the one-way PERMANOVA analyses, all variables were normalised without data transformation and a resemble matrix based on the Euclidean distances was calculated. Species richness $(\mathrm{S})$, the Shannon-Wiener index $\left(\mathrm{H}^{\prime}\right)$ and Pielou's evenness index $\left(\mathrm{J}^{\prime}\right)$ of the associated macrozoobenthic community were calculated using DIVERSE analysis. Afterward, one-way PERMANOVA (Type III) tests, using the resemble matrix based on the normalised Euclidean distances, were used to test for differences in the ecological indexes among treatments. In all PERMANOVA tests, the statistical significance of variance $(\alpha=0.05)$ was tested using 9999 permutations of residuals within a reduced model. When the number of unique permutations was lower than 150, the Monte Carlo $P$-value was considered. One-way PERMANOVA pairwise comparisons were also performed for all PERMANOVA tests.

In order to assess the relative contributions of the size and number of shells to the associated macrozoobenthic community, a distance-based linear modelling (DistLM) was also carried out. DistLM makes it possible to test the significance $(\alpha=0.05)$ of explanatory variables for a multivariate response variable in the form of a resemblance matrix (Anderson et al. 2008). For the DistLM, we selected the AIC (Akaike Information Criterion) based on the analyses on the Euclidean distance resemblance after normalisation of the data.

The observed mean density and richness of the single treatments (i.e. the ones that contained only one species) were used to make the comparison of the expected mean density and 
richness for the scenario treatments (i.e. before and after invasion by $C$. fluminea). The expected mean density and richness was always calculated taking into account the percentage of shells by species used in each scenario.

PRIMER analytical software (ver. 6.1.6, PRIMER-E Ltd, Plymouth, UK) with PERMANOVA+1.0.1 add-on (Anderson et al. 2008) was used for all statistical tests.

\section{Results}

\section{Treatment characteristics: differences among species}

The mean size and number of shells per bag varied among treatments (mean size: Pseudo- $F=483.44, P<0.05$; mean number: Pseudo- $F=1946.80, P<0.05)$. Pairwise tests indicated that most treatments were significantly different, with respect to the mean number of shells per bag, whereas for mean size of shells per bag only the 'Potomida' $v$. 'Mix natives' and the 'Corbicula' $v$. 'Mix actual' were not significantly different.

The treatments that contained the largest shells were 'Anodonta' ( $80.7 \pm 1.64 \mathrm{~mm})$, followed by 'Potomida' (66.1 \pm $0.92 \mathrm{~mm}$ ), 'Unio' (58.7 $\pm 0.75 \mathrm{~mm})$, 'Mix natives' (65.3 \pm $1.08 \mathrm{~mm})$, 'Corbicula' $(29.2 \pm 0.45 \mathrm{~mm})$ and 'Mix actual' $(28.3 \pm 0.27 \mathrm{~mm})$. The treatments that contained the highest number of shells per bag were those containing $C$. fluminea, namely 'Mix actual' (62.2 \pm 0.57 shells per bag) and 'Corbicula' ( $58.6 \pm 0.88$ shells per bag), followed by 'Unio' ( $27.4 \pm 0.34$ shells per bag), 'Mix natives' ( $20.5 \pm 0.31$ shells per bag), 'Potomida' ( $17.1 \pm 0.23$ shells per bag) and 'Anodonta' (13.5 \pm 0.27 shells per bag). Considering the mean size and number of shells per bag, the cluster analysis separated the treatments into two groups, one containing treatments with only native species and the other containing treatments with the invasive species C. fluminea (Fig. 3).

\section{Macrozoobenthic community}

A total of 35 macrozoobenthic taxa (14460 individuals), representing four phyla (Platyhelminthes, Mollusca, Annelida and Arthropoda) were associated with the empty bivalve shells. The two most diverse groups were the insects and molluscs, with 16 and 11 taxa respectively, accounting for $77.1 \%$ of the total number of taxa observed. The five most abundant taxa were the faucet snail Bithynia tentaculata (64.2\%), the worms of the subclass Oligochaeta (16.2\%), the Asian clam C. fluminea (6.7\%), the waterlouse Asellus aquaticus (4.9\%) and planarians of the family Dugesiidae (1.6\%), whereas the remaining 30 taxa made up to only $6.5 \%$ (Tables 1,2 ). The most abundant macrozoobenthic groups were the molluscs, annelids and crustaceans (Table 3), although no significant differences among the different treatments were observed (Table 3 ).

The highest values of density, biomass, species richness and diversity (Shannon-Wiener index) were observed in the treatments containing native species, with the exception of evenness (Pielou's index), where the highest value was observed for the treatment containing only $C$. fluminea shells (Fig. $4 a-e$ ). Nevertheless, significant differences in the ecological indices among treatments were recorded only for species richness (Pseudo$F=2.79, P<0.05$ ) (Fig. 4b). Pairwise comparisons indicated that 'Anodonta' $v$. 'Corbicula' $(t=2.26, P<0.05)$, 'Anodonta' $v$. 'Mix actual' $(t=2.77, P<0.05)$ and 'Potomida' $v$. 'Mix actual' $(t=2.24, P<0.05)$ were significantly different (Fig. $4 b)$.
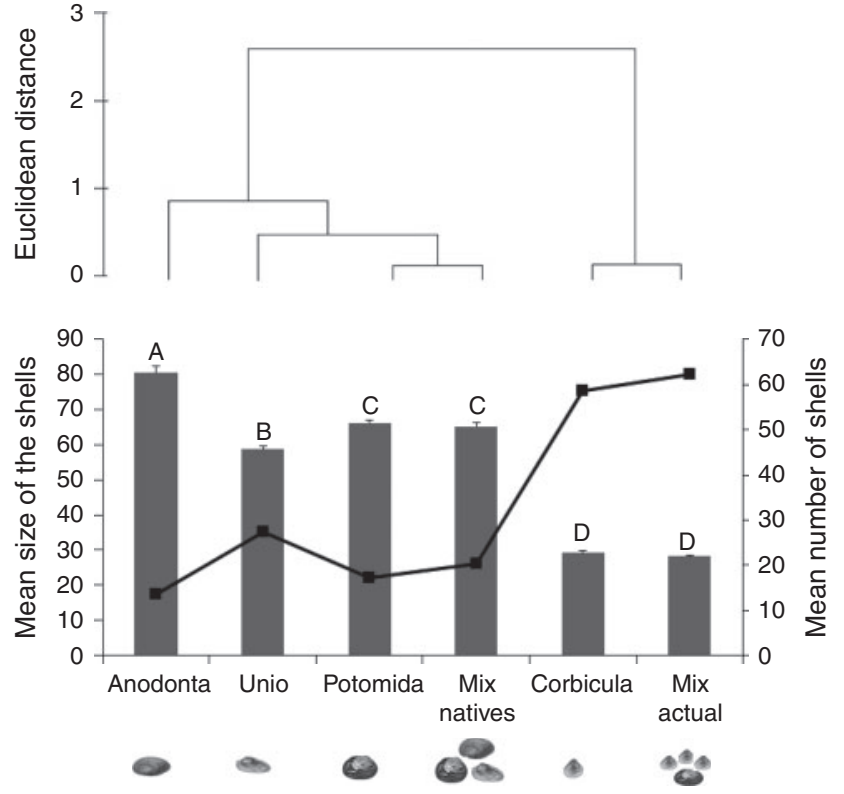

Fig. 3. Cluster with the mean ( \pm s.e.) size of the shells (grey bars) and mean $( \pm$ s.e. $)$ number of shells (black line) used in each treatment. Different letters indicate significant differences between them (one-way PERMANOVA pairwise tests; $P<0.05)$.

The DistLM analysis indicated that the number and the size of shells significantly influenced the macrozoobenthic community $(\mathrm{AIC}=83.29$, SS-trace $=16.22$, Pseudo- $F=4.28$, $P<0.05$ ); however, these two variables explained only $6.76 \%$ of the variance.

The observed mean density of macrozoobenthos between the two scenarios, before invasion by $C$. fluminea ('Mix natives') $\left(2067.4 \pm 473.0\right.$ individuals $\left.\mathrm{m}^{-2}\right)$ and after invasion by C. fluminea ('Mix actual') $\left(1533.3 \pm 298.0\right.$ individuals $\left.\mathrm{m}^{-2}\right)$, was higher than the expected mean density for each scenario ('Mix natives': $1947.8 \pm 445.0$ individuals $\mathrm{m}^{-2}$; 'Mix actual': $1398.5 \pm 272.0$ individuals $\mathrm{m}^{-2}$ ). Furthermore, when considering the richness, the pattern was different, because the observed mean richness before invasion by $C$. fluminea $(11.1$ species) and after invasion by $C$. fluminea ( 8.8 species) was lower than the expected mean values ('Mix natives': 11.4 species; 'Mix actual': 9.7 species).

\section{Discussion}

Our results indicate that the associated macrozoobenthic community was even across treatments, and that only small differences were detected between the scenarios. The only exception was species richness, with a richer associated fauna observed for the treatments 'Anodonta', 'Potomida', 'Unio' and 'Mix natives' as compared with the treatments containing the invasive C. fluminea (i.e. 'Mix actual' and 'Corbicula'). It is possible that the observed differences were due to structural and morphological differences between native and non-native shells, which could have accounted for a slightly different colonisation. However, detailed studies regarding the influence of shell thickness, roughness and shape (e.g. structural morphology, edge morphology, adductor scar morphology) in attracting 
Table 1. Mean ( \pm s.e.) density (individuals $\mathrm{m}^{-2}$ ) per treatment of the most representative macrozoobenthic-associated taxa

\begin{tabular}{|c|c|c|c|c|c|c|}
\hline \multirow[t]{2}{*}{ Taxonomic group } & \multicolumn{6}{|c|}{ Treatment } \\
\hline & 'Anodonta' & 'Potomida' & ‘Unio’’ & 'Corbicula' & 'Mix natives' & 'Mix actual' \\
\hline \multicolumn{7}{|l|}{ Platyhelminthes } \\
\hline Planariidae & $15.8 \pm 5.2$ & $3.3 \pm 1.8$ & $7.5 \pm 4.6$ & $4.2 \pm 2.9$ & $9.1 \pm 4.4$ & $5.0 \pm 3.6$ \\
\hline Dugesiidae & $38.3 \pm 14.1$ & $22.5 \pm 9.4$ & $30.0 \pm 14.8$ & $25.0 \pm 14.1$ & $31.8 \pm 17.5$ & $23.3 \pm 15.2$ \\
\hline \multicolumn{7}{|l|}{ Mollusca } \\
\hline Bithynia tentaculata & $1398.3 \pm 251.7$ & $1319.2 \pm 315.8$ & $1100.1 \pm 313.3$ & $777.5 \pm 135.0$ & $1304.5 \pm 399.2$ & $1059.2 \pm 267.5$ \\
\hline Corbicula fluminea & $85.8 \pm 16.8$ & $158.3 \pm 36.8$ & $100.8 \pm 11.9$ & $131.7 \pm 23.0$ & $128.0 \pm 19.5$ & $120.0 \pm 18.7$ \\
\hline Potamopyrgus antipodarum & $10.8 \pm 2.8$ & $22.5 \pm 9.2$ & $11.7 \pm 5.4$ & $15.0 \pm 6.9$ & $25.0 \pm 8.2$ & $13.3 \pm 5.9$ \\
\hline Valvata piscinalis & $6.7 \pm 3.3$ & $20.0 \pm 8.3$ & $10.8 \pm 2.2$ & $3.3 \pm 2.6$ & $9.1 \pm 2.7$ & $9.2 \pm 4.9$ \\
\hline \multicolumn{7}{|l|}{ Annelida } \\
\hline \multicolumn{7}{|l|}{ Hirudinea } \\
\hline Glossiphoniidae & $33.3 \pm 7.3$ & $29.2 \pm 6.8$ & $38.3 \pm 8.2$ & $18.3 \pm 3.2$ & $32.6 \pm 7.6$ & $18.3 \pm 7.1$ \\
\hline Erpobdellidae & $11.7 \pm 4.7$ & $17.5 \pm 6.4$ & $10.0 \pm 3.7$ & $17.5 \pm 5.0$ & $9.1 \pm 3.5$ & $15.8 \pm 7.9$ \\
\hline Oligochaeta & $306.7 \pm 65.8$ & $436.7 \pm 109.2$ & $195.0 \pm 35.8$ & $260.0 \pm 89.2$ & $350.0 \pm 85.0$ & $203.3 \pm 70.0$ \\
\hline \multicolumn{7}{|l|}{ Arthropoda } \\
\hline \multicolumn{7}{|l|}{ Crustacea } \\
\hline Asellus aquaticus & $112.5 \pm 26.7$ & $83.3 \pm 24.2$ & $109.2 \pm 36.7$ & $60.0 \pm 25.8$ & $122.0 \pm 47.5$ & $40.0 \pm 15.0$ \\
\hline \multicolumn{7}{|l|}{ Insecta } \\
\hline Elmidae & $10.0 \pm 5.7$ & $18.3 \pm 10.0$ & $10.0 \pm 7.3$ & $5.8 \pm 2.8$ & $7.6 \pm 2.8$ & $5.0 \pm 2.2$ \\
\hline Chironomidae & $10.8 \pm 3.5$ & $8.3 \pm 3.7$ & $12.5 \pm 4.2$ & $4.2 \pm 2.6$ & $12.1 \pm 5.2$ & $2.5 \pm 1.3$ \\
\hline Sialidae & $2.5 \pm 1.3$ & $4.2 \pm 1.4$ & $5.8 \pm 1.8$ & $2.5 \pm 1.8$ & $6.1 \pm 2.8$ & $1.7 \pm 1.1$ \\
\hline Limnephilidae & $3.3 \pm 2.6$ & $0.0 \pm 0.0$ & $0.0 \pm 0.0$ & $0.8 \pm 0.8$ & $3.0 \pm 1.7$ & $2.5 \pm 1.3$ \\
\hline Hydropsychidae & $1.7 \pm 1.1$ & $0.0 \pm 0.0$ & $1.7 \pm 1.7$ & $3.3 \pm 1.4$ & $1.5 \pm 1.0$ & $0.0 \pm 0.0$ \\
\hline Leptoceridae & $5.8 \pm 4.2$ & $5.8 \pm 1.8$ & $3.3 \pm 1.3$ & $3.3 \pm 1.4$ & $5.3 \pm 2.3$ & $5.0 \pm 5.0$ \\
\hline Leuctridae & $4.2 \pm 1.4$ & $0.0 \pm 0.0$ & $0.0 \pm 0.0$ & $0.8 \pm 0.8$ & $1.5 \pm 1.0$ & $0.0 \pm 0.0$ \\
\hline
\end{tabular}

Table 2. Mean ( \pm s.e.) biomass $\left(\mathrm{mg} \mathrm{DW}^{-2}\right)$ per treatment of the most representative macrozoobenthic-associated taxa

\begin{tabular}{|c|c|c|c|c|c|c|}
\hline \multirow[t]{2}{*}{ Taxonomic group } & \multicolumn{6}{|c|}{ Treatment } \\
\hline & 'Anodonta' & 'Potomida' & 'Unio' & 'Corbicula' & 'Mix natives' & 'Mix actual' \\
\hline \multicolumn{7}{|l|}{ Platyhelminthes } \\
\hline Planariidae & $2.8 \pm 1.1$ & $0.8 \pm 0.6$ & $4.6 \pm 3.2$ & $0.5 \pm 0.4$ & $2.7 \pm 2.2$ & $1.0 \pm 0.9$ \\
\hline Dugesiidae & $13.3 \pm 4.9$ & $7.9 \pm 3.4$ & $8.3 \pm 3.7$ & $8.3 \pm 4.4$ & $9.8 \pm 4.0$ & $8.2 \pm 5.5$ \\
\hline \multicolumn{7}{|l|}{ Mollusca } \\
\hline Bithynia tentaculata & $19166.0 \pm 2183.3$ & $13334.3 \pm 3025.0$ & $15838.8 \pm 4091.7$ & $9776.2 \pm 1683.3$ & $15671.2 \pm 3575.0$ & $11033.3 \pm 2008.3$ \\
\hline Corbicula fluminea & $8699.0 \pm 1775.0$ & $15590.9 \pm 3716.6$ & $9578.3 \pm 1983.3$ & $10794.2 \pm 2216.7$ & $14477.0 \pm 2250.0$ & $14660.9 \pm 3116.7$ \\
\hline Potamopyrgus antipodarum & $11.4 \pm 5.0$ & $20.3 \pm 6.4$ & $12.6 \pm 5.2$ & $18.9 \pm 7.8$ & $31.2 \pm 9.3$ & $18.9 \pm 7.3$ \\
\hline Valvata piscinalis & $5.3 \pm 3.3$ & $34.2 \pm 16.5$ & $27.2 \pm 9.2$ & $3.9 \pm 2.8$ & $22.1 \pm 10.7$ & $16.6 \pm 75.3$ \\
\hline \multicolumn{7}{|l|}{ Annelida } \\
\hline \multicolumn{7}{|l|}{ Hirudinea } \\
\hline Glossiphoniidae & $56.9 \pm 12.8$ & $44.6 \pm 39.7$ & $90.8 \pm 20.4$ & $133.5 \pm 70.8$ & $143.3 \pm 57.3$ & $28.4 \pm 13.8$ \\
\hline Erpobdellidae & $26.5 \pm 11.8$ & $44.5 \pm 18.8$ & $50.9 \pm 16.7$ & $56.9 \pm 17.7$ & $22.6 \pm 9.5$ & $48.3 \pm 27.4$ \\
\hline Oligochaeta & $60.0 \pm 13.5$ & $67.5 \pm 16.8$ & $25.9 \pm 3.8$ & $50.3 \pm 14.0$ & $51.1 \pm 13.1$ & $247.3 \pm 195.8$ \\
\hline \multicolumn{7}{|l|}{ Arthropoda } \\
\hline \multicolumn{7}{|l|}{ Crustacea } \\
\hline Asellus aquaticus & $13.2 \pm 2.6$ & $24.3 \pm 11.5$ & $14.7 \pm 4.3$ & $7.3 \pm 3.3$ & $15.5 \pm 6.1$ & $5.5 \pm 1.6$ \\
\hline \multicolumn{7}{|l|}{ Insecta } \\
\hline Elmidae & $3.8 \pm 2.3$ & $2.2 \pm 1.2$ & $1.5 \pm 1.1$ & $3.8 \pm 3.1$ & $1.4 \pm 0.8$ & $0.6 \pm 0.3$ \\
\hline Chironomidae & $5.8 \pm 2.9$ & $3.1 \pm 2.0$ & $1.3 \pm 0.4$ & $0.5 \pm 0.3$ & $1.8 \pm 1.2$ & $2.9 \pm 2.5$ \\
\hline Sialidae & $8.0 \pm 4.6$ & $12.7 \pm 4.6$ & $20.2 \pm 9.2$ & $9.8 \pm 6.9$ & $22.2 \pm 9.4$ & $7.0 \pm 4.7$ \\
\hline Limnephilidae & $41.8 \pm 40.8$ & $0.0 \pm 0.0$ & $0.0 \pm 0.0$ & $11.1 \pm 11.1$ & $57.4 \pm 32.8$ & $22.0 \pm 11.4$ \\
\hline Hydropsychidae & $5.3 \pm 2.8$ & $0.0 \pm 0.0$ & $2.0 \pm 2.0$ & $7.3 \pm 3.8$ & $0.2 \pm 0.2$ & $0.0 \pm 0.0$ \\
\hline Leptoceridae & $1.9 \pm 1.4$ & $2.8 \pm 1.3$ & $1.3 \pm 0.7$ & $4.3 \pm 3.4$ & $4.2 \pm 2.5$ & $0.9 \pm 0.5$ \\
\hline Leuctridae & $4.7 \pm 3.8$ & $0.0 \pm 0.0$ & $0.0 \pm 0.0$ & $0.2 \pm 0.2$ & $2.7 \pm 2.3$ & $0.0 \pm 0.0$ \\
\hline
\end{tabular}


Table 3. Mean ( \pm s.e.) density (individuals $\mathrm{m}^{-2}$ ) of the most representative macrozoobenthic-associated groups and PERMANOVA results

\begin{tabular}{lccccccc}
\hline $\begin{array}{l}\text { Taxonomic } \\
\text { group }\end{array}$ & 'Anodonta' & 'Potomida' & 'Unio' & 'Corbicula' & 'Mix natives' & 'Mix actual' & PERMANOVA \\
\hline $\begin{array}{l}\text { Total number of } \\
\text { individuals }\end{array}$ & $2083.3 \pm 307.0$ & $2160.0 \pm 380.0$ & $1659.2 \pm 359.0$ & $1337.5 \pm 236.0$ & $2067.4 \pm 473.0$ & $1533.3 \pm 298.0$ & Pseudo- $F=0.93, P=0.47$ \\
$\begin{array}{l}\text { Platyhelminthes } \\
\text { Mollusca }\end{array}$ & $54.2 \pm 18.6$ & $25.8 \pm 10.9$ & $37.5 \pm 19.2$ & $29.2 \pm 15.0$ & $40.9 \pm 20.2$ & $28.3 \pm 17.8$ & Pseudo- $F=0.37, P=0.88$ \\
Annelida & $152.5 \pm 268.0$ & $1526.7 \pm 307.0$ & $1234.2 \pm 323.0$ & $930.8 \pm 141.0$ & $1472.7 \pm 398.0$ & $1210.0 \pm 270.0$ & Pseudo- $F=0.62, P=0.71$ \\
Crustacea & $112.5 \pm 72.6$ & $483.3 \pm 112.0$ & $243.3 \pm 40.3$ & $295.8 \pm 87.2$ & $391.7 \pm 86.2$ & $237.5 \pm 80.3$ & Pseudo- $F=1.30, P=0.27$ \\
Insecta & $2930.6 \pm 605.0$ & $4027.8 \pm 24.0$ & $109.2 \pm 36.9$ & $60.0 \pm 25.8$ & $122.0 \pm 47.2$ & $40.0 \pm 15.4$ & Pseudo- $F=1.06, P=0.40$ \\
& & & $2027.8 \pm 336.0$ & $2465.3 \pm 727.0$ & $3263.9 \pm 719.0$ & $1979.2 \pm 669.0$ & Pseudo- $F=1.62, P=0.17$ \\
\hline
\end{tabular}

(a)
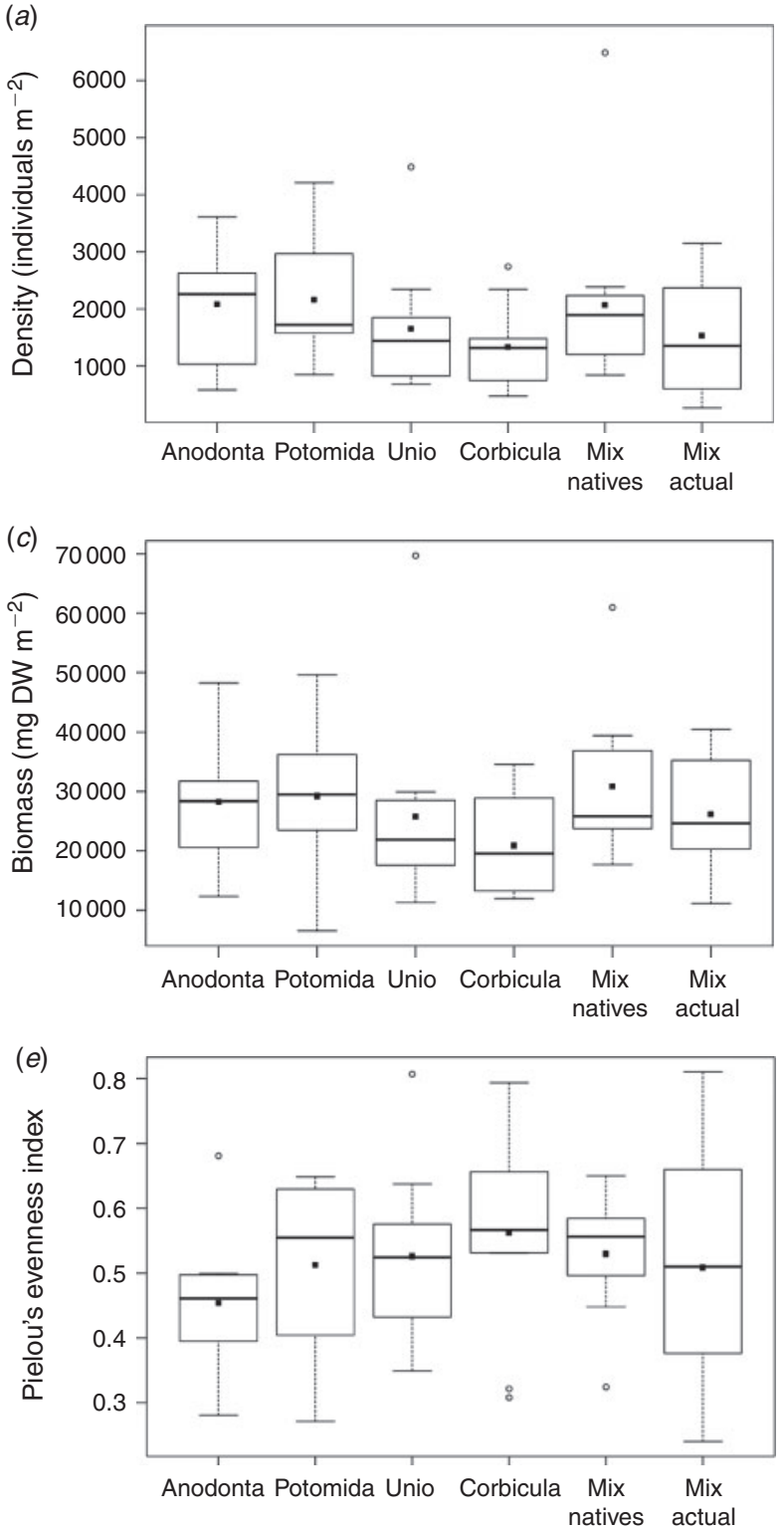
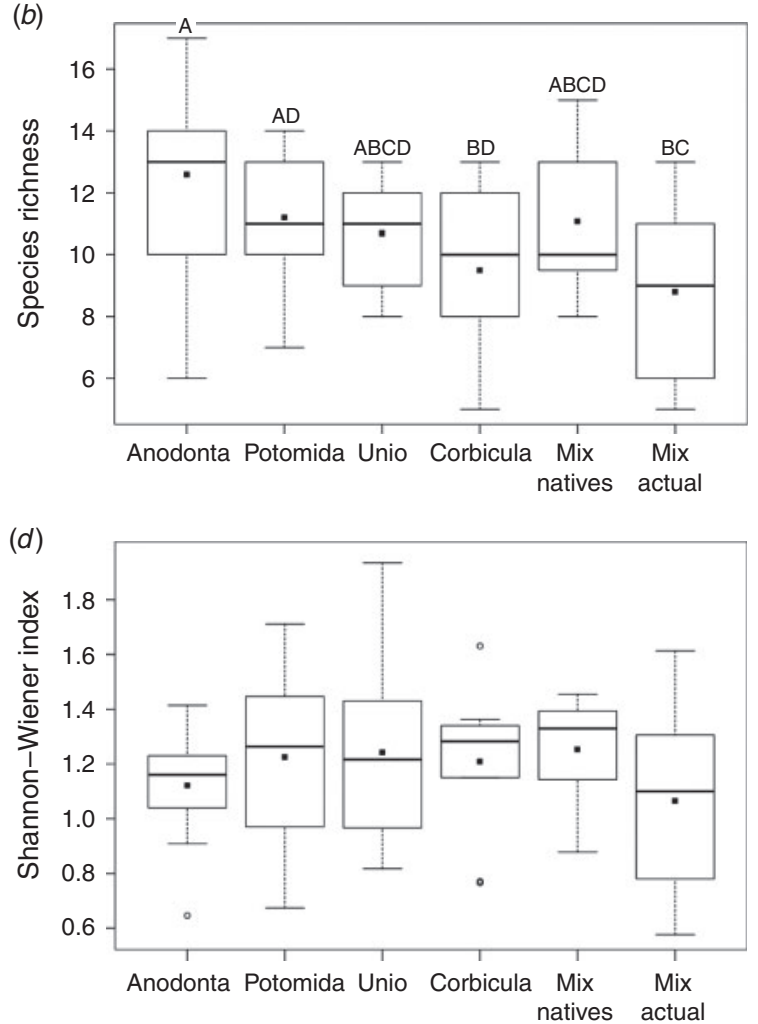

Fig. 4. Box plot of the $(a)$ density (individuals $\left.\mathrm{m}^{-2}\right),(b)$ species richness, $(c)$ biomass $\left(\mathrm{mg} \mathrm{DW} \mathrm{m}{ }^{-2}\right),(d)$ Shannon-Wiener index $\left(\mathrm{H}^{\prime}\right)$ and $(e)$ Pielou's eveness index $\left(\mathrm{J}^{\prime}\right)$ of the macrozoobenthic community. The intervals represent the standard deviation, the black square symbol represents the mean and the black line represents the median. Different letters indicate significant differences among treatments (one-way PERMANOVA pairwise tests; $P<0.05$ ). 
fauna should be conducted in order to provide more comprehensive and definitive conclusions.

The four bivalve species used in this study presented several morphological differences, namely outer-shell surface roughness, shell hardness, thickness and three-dimensional shape. The C. fluminea shells are very different morphologically relative to the shells of the native species, given that the outer-shell of the Asian clams presents a rough sculpture with raised concentric ribs, in contrast to the rather smooth and somewhat flat surface of the shells of the native species. The hardnesses of the shells are also remarkably different, with $P$. littoralis presenting a robust, thick, hard shell, whereas $C$. fluminea had a slightly less hard, thinner and 3-D-complex shell. Moreover, the shells of $U$. delphinus and $A$. anatina are thin and somewhat delicate (particularly that of A. anatina). Furthermore, possible chemical differences between the shells are expected, and this aspect could also have influenced the associated fauna; however, future detailed studies should be performed considering the lack of knowledge on this topic. These morphological and chemical differences in the shells between species are likely to be of importance when attracting fauna, although our experimental design cannot give a definitive answer regarding this issue.

The average size of the particles in the substratum can also influence the structure of the macrozoobenthic community (Reice 1980; Erman and Erman 1984). Large shells, compared to small ones, are normally associated with a fauna of high density and richness (Beckett et al. 1996; Giacobbe 2002; Gutierrez et al. 2003). Despite the mean shell size of native species being significantly larger than that of the non-native species, shell-size had only a marginal influence on the associated macrozoobenthos. As such, shell size should not be considered an important explanatory variable in this context, at least at our study site. Nevertheless, the diversity of structural elements in a habitat is important for the colonisation of the macrozoobenthic community (Bell et al. 1991). Diverse bivalve assemblages may support a denser and more diverse macrozoobenthic community than bivalve assemblages dominated by a single species or by a cluster of morphologically similar species. Indeed, heterogeneous and structurally complex habitats provide myriad microhabitats where associated fauna flourish (Allan 1975). Although distinct substratum preferences seem to be linked to different macrozoobenthic species (Allan 1975), this pattern was not recorded in the present study, with the associated fauna being evenly represented in all treatments. The only exception was species richness, which was significantly different. These results indicate that the empty shells of invasive species can partially play the same ecological function as the native species on the invaded ecosystem, as far as macrozoobenthos colonisation is concerned.

Interestingly, in this study a synergism between species could have occurred when they were available altogether, as this was observed when comparing the observed with the expected mean density values. The observed attracted much higher density values ('Mix natives': 25.8\% higher; 'Mix actual': $28.2 \%$ higher) of the associated fauna than was expected. A different pattern was observed for the richness, with lower richness values ('Mix natives': $2.7 \%$ lower; 'Mix actual': $10.1 \%$ lower) observed when compared to what was expected. In this case, it is possible that the presence of $C$. fluminea could have contributed to the lower values observed. Future detailed studies should be performed in order to better understand these results.

In this study we used empty shells. However, if we had experimented with live individuals the results could have been different. Previous studies performed with live Corbicula observed no effects on the benthic invertebrates (Hakenkamp and Palmer 1999; Hakenkamp et al. 2001; Karatayev et al. 2005; Werner and Rothhaupt 2007). Nonetheless, Zaiko et al. (2009) noted that the effect of live mussels on biodiversity was more pronounced than the effect of shell deposits. Spooner and Vaughn (2006) also observed an influence of live unionid mussels on the distribution and abundance of periphyton and invertebrates when compared with sham mussels (shells filled with sand), suggesting that the biological activities of bivalves offer ecological conditions to the benthic community beyond the physical habitat provided by the shells alone.

Given that empty shells of native and invasive species exerted a similar influence on the macrozoobenthic community, it seems reasonable to assume that $C$. fluminea shells can partially mimic the ecological role played by native bivalves, at least for the macrozoobenthic community. The high density of C. fluminea (represented by live individuals and empty shells) in the River Minho (see Sousa et al. 2008b, 2008d, 2008e) suggests that this species is probably influencing the whole system, including the macrozoobenthos that respond to the overall structural changes related mainly to the provision of a hard substrate (represented by the presence of their shells). These hard substrates can be used as a structural element for attachment, refuges to avoid predators, competitors, physical and physiological stress, and by affecting the transport of particles and solutes in the benthic environment, which may in turn influence different trophic levels (Vaughn et al. 2008; Ilarri et al. 2012, 2014). C. fluminea can supply prey for the higher trophic levels, and probably provide a different scenario to that observed when the native species occurred at higher densities. However, this discussion can only be speculative given the lack of detailed data regarding the macrozoobenthos before the invasion by $C$. fluminea in the River Minho, with further studies necessary in order to better understand exactly how $C$. fluminea influences different trophic levels in this system.

Recent, massive die-offs of freshwater bivalves have occurred in the River Minho owing to extreme climatic conditions (Sousa et al. 2008d, 2012; Ilarri et al. 2011), and according to the Intergovernmental Panel on Climate change (IPCC) these kinds of events will increase in frequency and intensity throughout Europe (IPCC 2007). Massive die-off events have resulted in a large accumulation of empty shells in some areas of the River Minho (Sousa et al. 2012). Following the die-off events, some species experienced a rapid population growth, whereas others were negatively affected (Sousa et al. 2008d). C. fluminea (e.g. dead and live) is capable of sustaining a high density of associated fauna (Ilarri et al. 2012, 2014 and present study). In fact, Ilarri et al. (2012) observed that the macrozoobenthic density, biomass and diversity positively responded to the increasing density of $C$. fluminea. Regardless of the influence of C. fluminea on some faunal groups (Ilarri et al. 2012), our results indicate that the composition of the macrozoobenthic community in the River Minho, taking into consideration only 
the availability of empty shells provided, probably did not change due to the Asian clam invasion, and will likely remain partially similar if native bivalves become locally extinct. However, differences in the life cycle and density between $C$. fluminea and the native bivalves means that the absolute number of live and empty Asian clam shells on the river bed is largely higher than that of native shells, thereby covering a large area of the riverine soft bottom and providing a large amount of hard substrata ready for colonisation.

To date, few studies comparing the associated fauna of native and invasive bivalve species have been conducted (see Kochmann et al. 2008; Markert et al. 2010; Wilkie et al. 2012), with our study being the first to investigate the influence of empty freshwater bivalve shells. Our results were similar only to those of Wilkie et al. (2012), whereas other studies presented conflicting evidence. Kochmann et al. (2008) and Markert et al. (2010) observed differences in the macrofaunal community associated with the invasive species Crassostrea gigas, which has hard and extremely rough shells, as compared to the native species Mytilus edulis (which has smooth and unruffled shells) in the Wadden Sea (Germany). The results of Markert et al. (2010) show that the fauna associated with $C$. gigas had higher density, biomass, richness and diversity, whereas Kochmann et al. (2008) only observed shifts in the abundance of dominant associated species. Wilkie et al. (2012) suggested that the similarities between the associated fauna of two bivalve species (i.e. one invasive and the other native) are due to the fact that both species are morphologically similar ecosystem engineers, further suggesting that the degree of morphological similarity between the invasive and native species may be a good predictor of the possible impacts. However, in the present study the selected species (e.g. native and invasive species) have morphological differences in their structure, mainly due to the size and roughness, although the associated fauna was very similar.

\section{Conclusions}

The empty bivalve shells of the invasive $C$. fluminea seem to be functionally equivalent to the native species in the River Minho, with almost no distinction being recorded on the associated macrozoobenthos (with the exception that species richness was higher in the native species compared to the treatments containing the invasive $C$. fluminea). Furthermore, small differences were detected between the scenarios with respect to conditions before and after invasion. The empty shells of the invasive species $C$. fluminea have been capable of partially replacing the ecological functions of empty shells from native species, at least for associated macrozoobenthic community.

\section{Acknowledgements}

Martina Ilarri is supported by a Post-doc grant (SFRH/BPD/90088/2012) from the Portuguese Foundation for Science and Technology - FCT through POPH/FSE funds. This study was conducted within the scope of the project ECO-IAS: Ecosystem-level impacts of an invasive alien species, supported by FCT and COMPETE funds (contract: PTDC/AAC-AMB/116685/2010) and was also partially supported by the European Regional Development Fund (ERDF) through COMPETE funds (PEst-C/MAR/LA0015/2011) and by FCT/MEC through Portuguese funds (PIDDAC - PEst-OE/BIA/UI4050/
2014). Special thanks to Felipe Ribas for the drawing of the shells and to Dr Ian Duggan and Rahel Zemoi for the English review. The authors also thank the two anonymous referees, who greatly improved the quality of the manuscript.

\section{References}

Allan, J. D. (1975). The distributional ecology and diversity of benthic insects in Cement Creek, Colorado. Ecology 56, 1040-1053. doi: $10.2307 / 1936145$

Anderson, M. J. (2001). A new method for non-parametric multivariate analysis of variance. Austral Ecology 26, 32-46.

Anderson, M. J., Gorley, R. N., and Clarke, K. R. (2008). 'PERMANOVA+ for PRIMER: Guide to Software and Statistical Methods.' (PRIMER-E: Plymouth, UK.)

Araujo, R., Moreno, D., and Ramos, M. A. (1993). The Asiatic clam Corbicula fluminea (Müller, 1774) (Bivalvia: Corbiculidae) in Europe. American Malacological Bulletin 10, 39-49.

Beckett, D. C., Green, B. W., and Thomas, S. A. (1996). Epizoic invertebrate communities on upper Mississippi River unionid bivalves. The American Midland Naturalist Journal 135, 102-114. doi:10.2307/2426876

Bell, S. S., McCoy, E. D., and Mushinsky, H. R. (1991). 'Habitat Structure: the Physical Arrangement of Objects in Space.' (Chapman and Hall: London.)

Bódis, E., Tóth, B., and Sousa, R. (2014). Massive mortality of invasive bivalves as a potential resource subsidy for the adjacent terrestrial food web. Hydrobiologia 735, 253-262. doi:10.1007/S10750-013-1445-5

Borthagaray, A. I., and Carranza, A. (2007). Mussels as ecosystem engineers: their contribution to species richness in a rocky littoral community. Acta Oecologica 31, 243-250. doi:10.1016/J.ACTAO. 2006.10.008

Buchman, N., Cuddington, K., and Lambrinos, J. (2007). A historical perspective on ecosystem engineering. In 'Ecosystem Engineers: Plants to Protists'. (Eds K. Cuddungton, J. E. Byers, W. G. Wilson and A. Hastings.) pp. 25-46. (Academic Press: Burlington, VT, USA.)

Corriero, G., and Pronzato, R. (1987). Epibiontic sponges on the bivalve Pinna nobilis. Marine Ecology Progress Series 35, 75-82. doi:10.3354/ MEPS035075

Crooks, J. A. (2002). Characterizing ecosystem-level consequences of biological invasions: the role of ecosystem engineers. Oikos 97, 153-166. doi:10.1034/J.1600-0706.2002.970201.X

Dudgeon, D., Arthington, A. H., Gessner, M. O., Kawabata, Z. I., Knowler, D. J., Lévêque, C., Naiman, R. J., Prieur-Richard, A. H., Soto, D., Stiassny, M. L. J., and Sullivan, C. A. (2006). Freshwater biodiversity: importance, threats, status and conservation challenges. Biological Reviews of the Cambridge Philosophical Society 81, 163-182. doi:10.1017/S1464793105006950

Erman, D. C., and Erman, N. A. (1984). The response of stream macroinvertebrates to substrate size and heterogeneity. Hydrobiologia 108, 75-82. doi:10.1007/BF02391635

Erwin, D. H. (2008). Macroevolution of ecosystem engineering, niche construction and diversity. Trends in Ecology \& Evolution 23, 304-310. doi:10.1016/J.TREE.2008.01.013

Giacobbe, S. (2002). Epibiontic mollusc communities on Pinna nobilis L. (Bivalvia, Mollusca). Journal of Natural History 36, 1385-1396. doi:10.1080/00222930110056892

Gutiérrez, J. L., Jones, C. G., and Strayer, D. L. (2003). Mollusks as ecosystem engineers: the role of shell production in aquatic habitats. Oikos 101, 79-90. doi:10.1034/J.1600-0706.2003.12322.X

Gutiérrez, J. L., Jones, C. G., and Sousa, R. (2014). Toward an integrated ecosystem perspective of invasive species impacts. Acta Oecologica 54, 131-138. doi:10.1016/J.ACTAO.2013.10.003

Hakenkamp, C. C., and Palmer, M. A. (1999). Introduced bivalves in freshwater ecosystems: the impact of Corbicula on organic matter dynamics in a sandy stream. Oecologia 119, 445-451. doi:10.1007/ S004420050806 
Hakenkamp, C. C., Ribblett, S. G., Palmer, M. A., Swan, C. M., Reid, J. W., and Goodison, M. R. (2001). The impact of an introduced bivalve (Corbicula fluminea) on the benthos of a sandy stream. Freshwater Biology 46, 491-501. doi:10.1046/J.1365-2427.2001.00700.X

Ilarri, M., and Sousa, R. (2012). Corbicula fluminea Müller (Asian clam). In 'A Handbook of Global Freshwater Invasive Species'. (Eds R. A. Francis.) pp. 173-183. (Earthscan: London.)

Ilarri, M. I., Antunes, C., Guilhermino, L., and Sousa, R. (2011). Massive mortality of the Asian clam Corbicula fluminea in a highly invaded area. Biological Invasions 13, 277-280. doi:10.1007/S10530-010-9833-5

Ilarri, M. I., Freitas, F., Costa-Dias, S., Antunes, C., Guilhermino, L., and Sousa, R. (2012). Associated macrozoobenthos with the invasive Asian clam Corbicula fluminea. Journal of Sea Research 72, 113-120. doi:10.1016/J.SEARES.2011.10.002

Ilarri, M. I., Souza, A. T., Antunes, C., Guilhermino, L., and Sousa, R. (2014). Influence of the invasive Asian clam Corbicula fluminea (Bivalvia: Corbiculidae) on estuarine epibenthic assemblages. Estuarine, Coastal and Shelf Science 143, 12-19. doi:10.1016/J.ECSS.2014. 03.017

IPCC (2007). Contribution of Working Group I to the Fourth Assessment Report of the IPCC. In 'Climate change 2007: The Physical Science'. (Eds S. Basis Solomon, D. Qin, M. Manning, Z. Chen, M. Marquis, K. B. Averyt, M. Tognor, and H. L. Miller.) pp. 1-18. (Cambridge University Press: Cambridge, MA.).

Karatayev, A. Y., Burlakova, L. E., Kesterson, T., and Padilla, D. K. (2003). Dominance of the Asiatic clam, Corbicula fluminea (Müller), in the benthic community of a reservoir. Journal of Shellfish Research 22, 487-493

Karatayev, A. Y., Lyubov, E. B., and Padilla, D. K. (2005). Contrasting distribution and impacts of two freshwater exotic suspension feeders, Dreissena polymorpha and Corbicula fluminea. In 'The Comparative Roles of Suspension-feeders in Ecosystems'. (Eds R. F. Dame and S. Olenin.) pp. 239-262. (Springer: Dordrecht, Netherlands.)

Karatayev, A. Y., Padilla, D. K., Minchin, D., Boltovskoy, D., and Burlakova, L. E. (2007). Changes in global economies and trade: the potential spread of exotic freshwater bivalves. Biological Invasions 9, 161-180. doi:10.1007/S10530-006-9013-9

Kochmann, J., Buschbaum, C., Volkenborn, N., and Reise, K. (2008). Shift from native mussels to alien oysters: differential effects of ecosystem engineers. Journal of Experimental Marine Biology and Ecology 364, 1-10. doi:10.1016/J.JEMBE.2008.05.015

Markert, A., Wehrmann, A., and Kröncke, I. (2010). Recently established Crassostrea-reefs versus native Mytilus-beds: differences in ecosystems engineering affects the macrofaunal communities (Wadden Sea of Lower Saxony, southern German Bight). Biological Invasions 12 , 15-32. doi:10.1007/S10530-009-9425-4

McMahon, R. F. (2000). Invasive characteristics of the freshwater bivalve Corbicula fluminea. In 'Nonindigenous Freshwater Organisms: Vectors, Biology and Impacts'. (Eds R. Claudi and J. H. Leach.) pp. 315-343. (Lewis Publisher: New York.)

McMahon, R. F. (2002). Evolutionary and physiological adaptations of aquatic invasive animals: $r$ selection versus resistance. Canadian Journal of Fisheries and Aquatic Sciences 59, 1235-1244. doi:10.1139/F02-105

Nyman, K. J. (1953). Observations on the behavior of Gobious microps. Acta Societatis pro Fauna et Flora Fennica 69, 1-11.

Palacios, R., Armstrong, D. A., and Orensanz, J. (2000). Fate and legacy of an invasion: extinct and extant populations of the soft-shell clam (Mya arenaria) in Grays Harbor (Washington). Aquatic Conservation: Marine and Freshwater Ecosystems 10, 279-303. doi:10.1002/1099-0755 (200007/08) $10: 4<279::$ AID-AQC412>3.0.CO;2-I

Rabaoui, L., Tlig-Zouari, S., Katsanevakis, S., and Hassine, O. K. B. (2007) Comparison of absolute and relative growth patterns among five Pinna nobilis populations along the Tunisian coastline: an information theory approach. Marine Biology 152, 537-548. doi:10.1007/S00227007-0707-Z

Reice, S. R. (1980). The role of substratum in benthic macroinvertebrate microdistribution and litter decomposition in a woodland stream. Ecology 61, 580-590. doi:10.2307/1937424

Ricciardi, A., Whorieskey, F. G., and Rasmussen, J. B. (1997). The role of zebra mussel (Dreisseina polymorpha) in structuring macroinvertebrate communities on hard substrata. Canadian Journal of Fisheries and Aquatic Sciences 54, 2596-2608. doi:10.1139/F97-174

Simberloff, D., Martin, J. L., Genovesi, P., Maris, V., Wardle, D. A., Aronson, J., Courchamp, F., Galil, B., García-Berthou, E., Pascal, M., Pyšek, P., Sousa, R., Tabacchi, E., and Vilà, M. (2013). Impacts of biological invasions: what's what and the way forward. Trends in Ecology \& Evolution 28, 58-66. doi:10.1016/J.TREE.2012.07.013

Sousa, R., Guilhermino, L., and Antunes, C. (2005). Molluscan fauna in the freshwater tidal area of the River Minho estuary, NW of Iberian Peninsula. Annales de Limnologie - International Journal of Limnology 41, 141-147. doi:10.1051/LIMN/2005009

Sousa, R., Rufino, M., Gaspar, M., Antunes, C., and Guilhermino, L. (2008b). Abiotic impacts on spatial and temporal distribution of Corbicula fluminea (Müller, 1774) in the River Minho estuary, Portugal. Aquatic Conservation: Marine and Freshwater Ecosystems $\mathbf{1 8}$ 98-110. doi:10.1002/AQC.838

Sousa, R., Morais, P., Antunes, C., and Guilhermino, L. (2008c). Factors affecting Pisidium amnicum (Müller, 1774; Bivalvia: Sphaeriidae) distribution in the River Minho Estuary: consequences for its conservation. Estuarine, Coastal and Shelf Science 31, 1198-1207.

Sousa, R., Nogueira, A. J. A., Gaspar, M., Antunes, C., and Guilhermino, L. $(2008 d)$. Growth and extremely high production of the non-indigenous invasive species Corbicula fluminea (Müller, 1774): possible implications for ecosystem functioning. Estuarine, Coastal and Shelf Science 80, 289-295. doi:10.1016/J.ECSS.2008.08.006

Sousa, R., Dias, S., Freitas, V., and Antunes, C. (2008e). Subtidal macrozoobenthic assemblages along the River Minho estuarine gradient (north-west Iberian Peninsula). Aquatic Conservation: Marine and Freshwater Ecosystems 18, 1063-1077. doi:10.1002/AQC.871

Sousa, R., Gutiérrez, J. L., and Aldridge, D. (2009). Non indigenous bivalves as ecosystem engineers. Biological Invasions 11, 2367-2385. doi:10.1007/S10530-009-9422-7

Sousa, R., Ilarri, M., Souza, A. T., Antunes, C., and Guilhermino, L. (2011). Rapid declining trend of the greater European peaclam at the periphery of its distribution. Annales de Limnologie - International Journal of Limnology 47, 211-219. doi:10.1051/LIMN/2011041

Sousa, R., Varandas, S., Cortes, R., Teixeira, A., Lopes-Lima, M., Machado, J., and Guilhermino, L. (2012). Massive die-offs of freshwater bivalves as resource pulses. Annales de Limnologie - International Journal of Limnology 48, 105-112. doi:10.1051/LIMN/2012003

Sousa, R., Novais, A., Costa, R., and Strayer, D. L. (2014). Invasive bivalves in fresh waters: impacts from individuals to ecosystems and possible control strategies. Hydrobiologia 735, 233-251. doi:10.1007/S10750012-1409-1

Spooner, D. E., and Vaughn, C. C. (2006). Context-dependent effects of freshwater mussels on stream benthic communities. Freshwater Biology 51, 1016-1024. doi:10.1111/J.1365-2427.2006.01547.X

Strayer, D. L. (2009). Twenty years of zebra mussels: lessons from the mollusk that made headlines. Frontiers in Ecology and the Environment 7, 135-141. doi:10.1890/080020

Strayer, D. L. (2010). Alien species in fresh waters: ecological effects, interactions with other stressors, and prospects for the future. Freshwater Biology 55, 152-174. doi:10.1111/J.1365-2427.2009.02380.X

Strayer, D. L., and Dudgeon, D. (2010). Freshwater biodiversity conservation: recent progress and future challenges. Journal of the North American Benthological Society 29, 344-358. doi:10.1899/ $08-171.1$ 
Tachet, H., Richoux, P., Bournaud, M., and Usseglio-Polaterra, P. (Eds) (2003). 'Invertébrés D’Eau Douce: Systématique, Biologie, Écologie.' (CNRS Editions: Paris.)

Vaughn, C. C., and Hakenkamp, C. C. (2001). The functional role of burrowing bivalves in freshwater ecosystems. Freshwater Biology 46, 1431-1446. doi:10.1046/J.1365-2427.2001.00771.X

Vaughn, C. C., Nichols, S. J., and Spooner, D. E. (2008). Community and foodwebs ecology of freshwater mussels. Journal of the North American Benthological Society 27, 409-423. doi:10.1899/07-058.1

Vilà, M., Basnou, C., Pyšek, P., Josefsson, M., Genovesi, P., Gollasch, S., Nentwig, W., Olenin, S., Roques, A., Roy, D., Hulme, P. E., and DAISIE partners (2010). How well do we understand the impacts of alien species on ecosystem services? A pan-European cross-taxa assessment. Frontiers in Ecology and the Environment 8, 135-144. doi:10.1890/080083
Werner, S., and Rothhaupt, K. O. (2007). Effects of the invasive bivalve Corbicula fluminea on settling juveniles and other benthic taxa. Journal of the North American Benthological Society 26, 673-680. doi:10.1899/ 07-017R.1

Wilkie, E. M., Bishop, M. J., and O'Connor, W. A. O. (2012). Are native Saccostrea glomerata and invasive Crassostrea gigas oysters' habitat equivalents for epibenthic communities in south-eastern Australia? Journal of Experimental Marine Biology and Ecology 420-421, 16-25. doi:10.1016/J.JEMBE.2012.03.018

Zaiko, A., Daunys, D., and Olenin, S. (2009). Habitat engineering by the invasive zebra mussel Dreissena polymorpha (Pallas) in a boreal coastal lagoon: impact on biodiversity. Helgoland Marine Research 63, 85-94. doi:10.1007/S10152-008-0135-6 